\title{
Development of Participative Management System in Learning Environment Management for Small Sized Primary Schools
}

\author{
Prasertsak Hernthaisong ${ }^{1}$, Chaiyuth Sirisuthi ${ }^{1} \&$ Kanjana Wisetrinthong ${ }^{1}$ \\ ${ }^{1}$ Faculty of Education, Mahasarakham University, Thailand \\ Correspondence: Prasertsak Hernthaisong, Faculty of Education, Mahasarakham University, Thailand. Tel: \\ 66-812-825-898. E-mail: psk4489@gmail.com
}

Received: August 8, 2016

doi:10.5539/ies.v10n2p166
Accepted: September 17, $2016 \quad$ Online Published: January 30, 2017

URL: http://dx.doi.org/10.5539/ies.v10n2p166

\begin{abstract}
The research aimed to: 1) study the factors of a participative management system in learning environment management, 2) study the current situation, desirable outcomes, and further needs for developing a participative management system in learning management, 3) develop a working participative management system, and 4) assess the system's viability by studying the findings from usage of the system in the context of a small sized primary school. Research and Development process was implemented by analyzing the documents, theoretical approaches and related research literature. Then, the chosen factors used in the system were investigated by seven experts. The current situation, desirable outcomes, and further needs for developing a participative management system in learning environment management for small sized primary schools were studied by using a questionnaire that asked participants for their opinions, measuring using a 5-point Likert scale. Data were analyzed by calculating the Mean, Standard Deviation, and ( $\left.\mathrm{PNI}_{\text {modified }}\right)$. The development of the system was implemented by conducting field trip studies in schools recommended for their effective learning management system and use of best practices. The system was outlined, and the handbook was provided to implement the system. In addition, the propriety of both the proposed system and its handbook was investigated by nine experts. The results show that 21 sub-factors were considered in the development of the participative management system in learning environment management for small sized primary schools. These included six input factors, six process factors, seven product factors, and two feedback factors, each of which were assessed at the highest level of propriety by the panel of experts. The overall current situation was judged to be at a "Moderate" level of propriety, and the sense of desirable outcomes was assessed at the highest level of propriety. The needs for further development were ranked in order from high to low as follows: feedback factor, input factor, product factor, and process factor respectively. The system evaluative finding by experts found that in the overall propriety was assessed at the highest level. The standards of feasibility, propriety, utility, and system design were all rated at the highest level. In addition, the handbook for system implementation was also found to be at the highest level of propriety.
\end{abstract}

Keywords: participative management system, learning environment management, small sized primary schools

\section{Introduction}

The Ministry of Education's policy of Educational Reform during the second decade (2009-2018) was based on the guidelines of its vision that "Thai people could have quality lifelong learning." There were 3 main issues of the Ministry's objectives, including: 1 ) the development of educational quality and standard as well as learning for Thai people; 2) the increase of overall quality and educational opportunity and learning; 3 ) the promotion of participation from every division in educational administration and management. Four guidelines for educational reform and learning in the new plan were systematically determined including: the development of Thai people's quality, the development of teachers, the development of schools and learning sources, and the development of new administration and management. (Office of the Education Council, 2009) The major principles of the latest educational reform of the Ministry of Education were: 1) School-Based Decision Making, in which the schools should be the centers of decision making, and to be free to make decisions based on the students' benefit, 2) Collaboration, in which staff members of many divisions of educational management or stakeholders in educational management should be invited to express their opinions or offered levels of control and care; 3 ) Administrative and Managerial Decentralization, in which the educational management in academics, budget, 
staff management, and general management will be the responsibility of the local Educational Service Area and schools; and 4) Accountability (Office of the Basic Education Commission, 2007).

According to a survey by the Ministry of Education, it was found that there were 15,506 small sized schools out of 30,922 schools or $50.15 \%$, under jurisdiction of Office of Basic Education Commission including schools with fewer than 120 students, being responsible for $14.30 \%$ of total number of students. (Office of The Basic Education Commission, 2014) These schools are faced with problems of educational administration and management since they could not offer administration and management as well as instructional management effectively. Since there were many limitations such as the lack of teachers, no teachers in every class, lack of instructional media and modern material and equipment, insufficient budget for public utility expenditure. As a result, the students' learning achievement was in "Low" level. Furthermore, the staffs' morale was not in good condition (Ponsima, 2007).

During the Third Round of External Quality Assessment (2011-2015) during the 2011 budget year, 7,985 schools out of 34,404 schools were evaluated. It was found that 333 schools or $4.17 \%$ were evaluated at the "Very Good" level, 5,347 schools or $67.09 \%$ were assessed at the "Good" level, and 2,295 schools or $28.74 \%$ were at the "Uncertified" level. Of these uncertified schools, 2,119 schools were under the jurisdiction of Office of The Basic Education Commission. It was further found that most of them were in the northeast region and most of the uncertified schools were small sized schools (Pon-rung-roj, 2012).The learning environment is a situation affecting human beings' learning directly and indirectly, both in concrete and abstract forms. The Concrete Environment Situation or Physical Environmental Situation consisted of different situations designed by human beings such as the buildings and site, tables and chairs, equipment and. Media. It also includes natural things such as trees, plants, landscape, and weather. The Psychological Environmental Situation includes value systems as major parts of the culture, social groups and the knowledge, thoughts, feelings, and attitudes whether from oneself or others. For McVey (1989), the physical learning environment includes the light, color, noise, space, furniture, and characteristics of a learning place. The abstract or psychological environmental situation includes the classroom climate and social groups affecting students' learning. The learning environmental situation is clearly very important for students' learning. The learning environment has a direct effect on the support for student learning, and has a direct effect on the students' activities since many of these factors could help to facilitate or obstruct the students' action. The management of details like furniture or equipment might be appropriate with an adult group but might not be suitable with small group. The impact of student support could affect the teacher-student interaction since it could stimulate one's learning as well as create positive relationship which would be relevant to individual differences. There were 3 types of learning environmental situations including: 1) Physical Environmental Situation, 2) Psychological Environmental Situation, and 3) Social Environmental Situation (Sri-fa, 2013).It was supported by Hoksuwan's approach (2008) which found that the learning environmental situation could significantly affect the instructional management as well as students' learning, because it can stimulate the students' emotions and intelligence (Rooncharoen \& Sri-pai-roje, 2011).Any system of instructional management should be aware of different aspects of learning environmental situations carefully and strictly in order to have a positive influence on the students' learning. It was necessary for the learning environmental situation to be administered systematically, efficiently and effectively on the students' learning. In fact, however, it was noticeable that the learning environmental situations did not receive sufficient attention. They were often overlooked until they may cause a clear disadvantage to students' learning. Therefore, if the administrators, teachers, and related persons could be aware of the significance of these learning environmental situations, the comprehension, and the learning environmental management which would affect the students' learning, the students' learning would be better. Every division would need to collaborate in the administration and management for implementation to truly occur. In the $21^{\text {st }}$ Century, many writers and educators have discussed learning environmental situations. Specifically, in the United States, the characteristics were stated as follows: (Sanrattana, 2013) 1) the Online Classroom, such as distance learning by computer, simulation training or online interactions obtained from general classroom so that the students would be able to learn and work or do their housework simultaneously; 2) Hybrid Learning, which combines traditional teaching methods with online methods; 3) The Architecture Studio Model was the education pattern in studios in which the progressive development of works could be revealed openly, and the students would be able to see what being done by the others; 4) Technology-enabled Active Learning, in which the learning environmental situation of the classroom was organized to facilitate student-student interactions and student-teacher interactions using group seating with each student using a notebook computer, internet network, projector, and whiteboard around the classroom. Furthermore, it was stated by Heick (2014) that wherever it occurs, even in University of Sydney or Mississippi Elementary or any place, one thing needed to be considered by the teacher called intellectual alert situation like the student-centered classroom. Moreover, Nair (2007) observed that the trend for schools during 
the $21^{\text {st }}$ century was not only the learning place but also the gateway into the learning world since there would be computers ready to be used in every place and at all times. The wireless network and internet could be accessed, more intensive technology could be used, and informal learning would be more greatly emphasized. Furthermore, furniture would be designed more imaginatively, more services would be focused on, and the levels of partnerships with other schools or universities would be increased.

The management of participative learning within every related division has become more widespread in schools and universities of many countries. Collaboration in every division would receive greater support as one part of school and university structures because collaborative working was a process of persons, organizations, or work units that needed to occur. It was based on the awareness of school staffs or related persons' value. Consequently, the level of decision making, collaboration, investment, and responsibility of school staffs as well as related persons would be increased. The school administrators played their role in searching for collaboration and development of the administrative and managerial system with cooperation from every division. The goal was collaboration in work practice and gaining collaborative power from various aspects which would lead to the increased efficiency and effectiveness of work practice in both qualitative and quantitative aspects, and improvements in educational management (Bush \& Middlewood, 2005).

The school is responsible for the work units for educational management, the promotion for students' quality of life, and problem solving in a social crisis. The participatory learning management system should be applied in every division, and guidelines should be applied for developing the students' quality with appropriate applications for each context. The implementation should be performed systematically. The collaboration should involve staffs from every division, which would bring about the students' quality development more effectively. As a result, the educational management could accomplish its goal. The researcher, as a school administrator of a small sized school, was aware of the significance as well as necessity for learning environmental management because it was a major responsibility to be implemented for enhancing the students' learning as much as possible. Therefore, I was interested in developing the system of participatory learning environmental management in providing the a proper management system for the learning environmental for small sized primary schools in order to further improve the educational quality of other small sized schools.

\section{Objectives of Study}

The research goals were: 1) to study the factors of a participative management system in learning environment management for small sized primary schools; 2 ) to study the current situation, desirable outcomes, and further needs for developing a participative management system in learning management for small sized primary schools. 3) to develop a working system appropriate for small sized primary schools. 4) to study the findings from the usage of the system as implemented in a small sized primary school.

\section{Method and Instruments}

Research and Development process included four phases as follows:

Phase 1: Analysis of the documents, theoretical approaches and related research literature led to the development of key factors, which were investigated by seven experts.

Phase 2: the current situation, desirable outcomes, and needs for further development were studied by using a questionnaire that asked participants their opinions on the above factors, and scored according to a 5-point Likert scale. The participants in this study were 1,810 school administrators, academic teachers, the president of local school boards, parent representatives, and community leaders of the communities of the sample schools, all of which were small sized primary schools in northeastern Thailand. Data were analyzed by calculating the Mean $(\bar{X})$, Standard Deviation (S.D.), and ( $\left.\mathrm{PNI}_{\text {modified }}\right)$.

Phase 3: The management system was implemented by field trip study in schools with effective learning management systems and known for their best practices. The system was outlined, and the handbook for implementation was established. Before that, the propriety of both the system and its handbook were investigated by nine experts.

Phase 4: the findings were studied by applying the developed system in a small sized primary school.

\section{Results}

With respect to the stated research objectives, the results were as follows:

There were 21 sub-factors of a participative management system identified, including six input factors, six process factors, seven product factors, and two feedback factors. A panel of experts, evaluating these results, found that every factor achieved propriety at the highest level. 
The findings found that the overall current situation was assessed at a moderate level. The overall desirable outcomes factor was assessed at the highest level. The needs for further development were ranked in order from high to low as follows: feedback factor, input factor, product factor, and process factor.

The six input factors included: 1) administrators and policy managers putting the system into practice; 2) teachers and staffs; 3) students; 4) parents; 5) local school boards; and 6) community leaders. Process factors consisted of six factors including: 1) management inside the classroom; 2) management outside the classroom; 3) personnel development of teachers; 4) development of teachers and teaching; 5) implementation of positive discipline for students; and 6) fostering the development of interaction among teachers, students, and parents. Output factors consisted of seven factors including: 1) classroom quality; 2) learning resources outside the classroom; 3) teachers had appropriate personalities; 4) teachers had good teaching behavior; 5) students had desirable characteristics; 6) good interactions among teachers, students, and parents; and 7) all stakeholders were satisfied with the participative management system. Feedback factors consisted of two factors: 1) reporting; and 2) improvement and correction. The system evaluative findings by the panel of experts found that the overall propriety was rated at the highest level. The standard evaluative findings of feasibility, propriety, utility, and system design were all assessed at the highest level. In addition, the evaluative findings of the handbook for system implementation found it to be at the highest level.

The structure of the resulting system is shown in Figure 1:

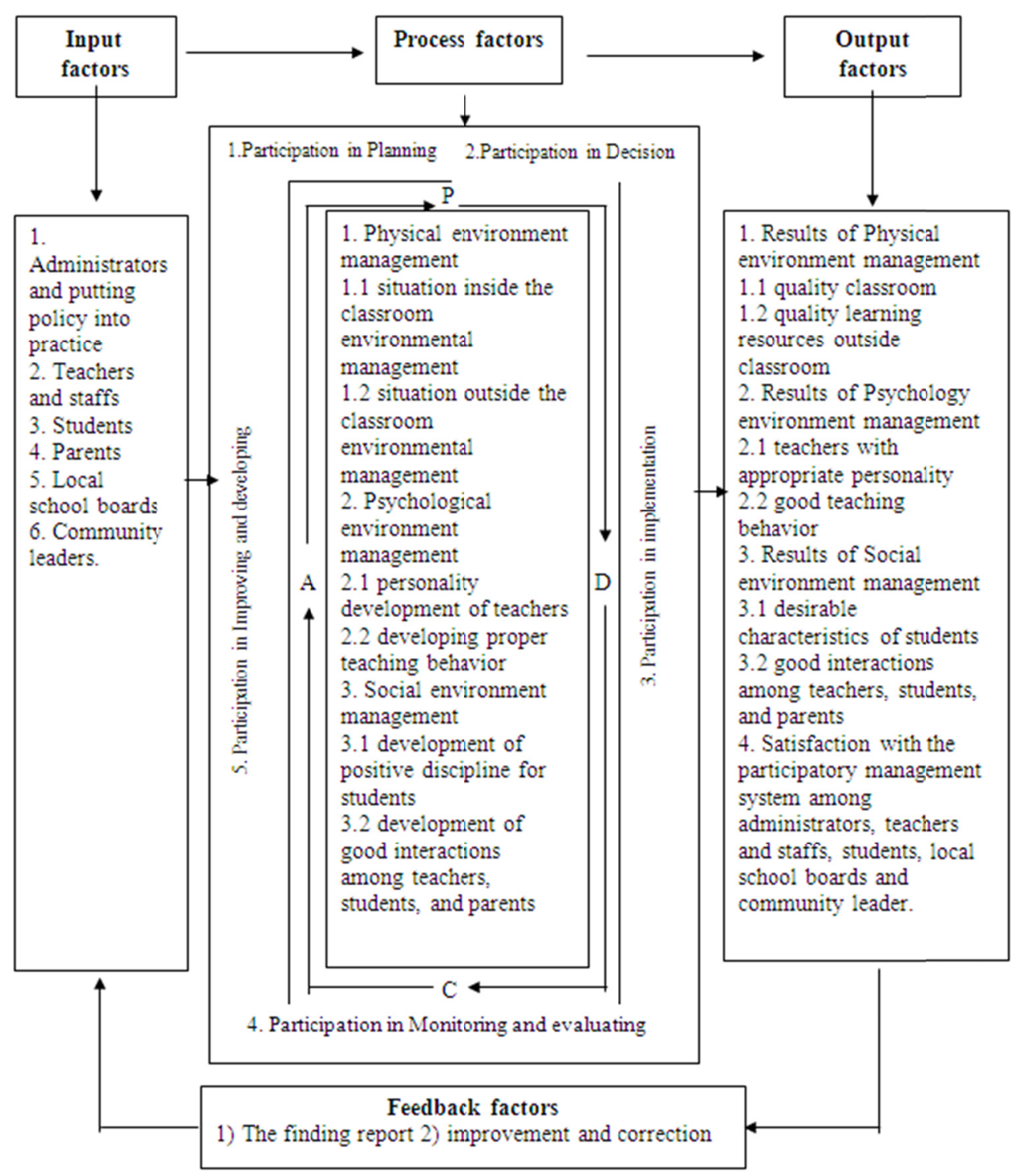

Figure 1. Participative management system in learning environment management for small sized primary schools 
The findings based on system usage data found that: 1) the overall classroom quality was higher than $80 \%$; 2 ) the overall quality of outside classroom learning sources, was at the highest level; 3) the overall appropriate personality of teachers was at the highest level; 4) the good teaching behavior of teachers was overall at the highest level; 5) the desirable characteristics of students were in good and excellent levels, for 94.21\%; 6) the relationships among teachers, students, and parents, were overall at the highest level; and 7) the overall satisfaction with the system of all related people was at the highest level.

\section{Conclusions and Discussions}

During the development of a participative management system that provides learning environmental management of small sized primary schools, the research findings revealed certain issues to be discussed as follows:

There were 21 sub-factors in the development of the participative environmental management system: six input factors, six process factors, seven output factors, and two feedback factors. The findings were investigated by experts, who found that every factor was rated for propriety at the highest level. This can be attributed to the researcher's study in related approaches, theories, and literatures of system development. It was found that most of the systems consisted of input factors, process factors, product factors, and feedback factors. This finding is supported by Schoderbek's (1990) classification of Elements of Systems including Input, Process, Output, and Feedback Factors. Likewise, Lunenberg and Ornstein (1996) stated that the element of a system should consist of Input, Process, Output, and Feedback Factors. The additional one is the Environmental Factor. The sub-factor of Input included putting the administrators and policy into practice, teachers and staffs, students, parents, school boards, and community leaders. For the sub-factor of Process, there were interesting issues to be discussed since the research findings of the process of the system were comprised of environmental situation management inside the classroom, environmental situation management outside the classroom, personality development of teachers, development of teaching behavior of teachers, positive discipline of students, and development of good interactions among teachers, students, and parents. Previous literature suggests that these issues were important in developing learning environmental management systems in schools. It was supported by many research studies, for instance, Sergiovanni (1999), who concluded that the characteristics of effective schools should include the following factors: 1) student-centered approaches should be emphasized; 2) good academic performance; 3) instructional management for enhancing the students' learning; 4) positive school climate; 5) group interaction enhancement; 6) staff development should be widely provided; 7) participatory leadership; 8) creative problem solving should be promoted; and 9) parents and community.

This study assessed the current situation at a "moderate" level. The overall desirable outcomes were assessed at the highest level. For development of future needs, highest was the Feedback factor. This apparently is because the context situation is liable to change. Consequently, the schools under Office of The Basic Education Commission were likely to change their size into small sized schools (there were fewer than 120 students in many schools) increasing as the population decreases. Consequently, the resources were not used efficiently. The allocation of teachers, staff budgets, and improvement of educational quality level were issues that caused many small sized schools to include low level problem situations in the quality of their educational management. This has been documented from scores on the national O-NET examination, which found that small sized schools had lower learning achievement at every level and in every geographical area than those of other schools. (Office of The Basic Education Commission, 2014) As the population tended to decrease, schools had to adjust to become small sized schools. Therefore, the student-teacher ratios and size of classrooms were lower than the standard criterion. Furthermore, a number of small sized schools in the most remote areas and far away from progress, such as schools atop high hills or on small islands presented difficulties to students in their journeys. Most administrators in these small sized schools lacked school management skills. Another problem was the age of students who had to move with their parents being employed in different areas, another cause of problems and obstacles in doing school work. In terms of the instructional problems, it was found that most of teachers lacked skills in instructional activity management, since there were often classes with no teachers, and there were sometimes too few students in each class. The teachers could not teach full time with full potential because they had many responsibilities rather than teaching. The curriculum as well as lesson plans were not relevant to school context. There were limited number of instructional media and instructional resources, caused by their small budgets. The technological and communicational media were limited, too, and could not be employed efficiently. In conclusion, the outside environmental situation was the factor facilitating the development of opportunity for students' learning quality in small sized schools. Moreover, the inside environmental situation was the weak point of administration and management for enhancing the students' educational quality. So, the current research findings in the current situation and desirable outcomes of participatory management process for 
providing the learning environmental situation was studied by the researcher, and led to the designing of the most suitable system for small sized Primary Schools.

Six Input Factors were studied, including: 1) the administrators and putting policy into practice; 2) teachers and staffs; 3) students; 4) parents; 5) local school boards; and 6) community leaders. There were six Process Factors, including: 1) the situation inside the classroom; 2) the situation outside the classroom; 3) personality development of teachers; 4) developing proper teaching behavior; 5) development of positive discipline for students; and 6) good interactions among teachers, students, and parents. There were seven Output Factors including 1) quality classroom; 2) quality learning resources outside classroom; 3) teachers with appropriate personalities; 4) good teaching behavior; 5) desirable characteristics of students; 6) good interactions among teachers, students, and parents; and 7) satisfaction with the participatory management system among administrators, teachers and staffs, students, local school boards and community leaders. There were two Feedback Factors: 1) the finding report, and 2) improvement and correction. The panel of experts assessed the propriety of the system at the highest level. The assessment of standard criterion, propriety, utility, and accuracy standards were all found to be at the highest level. In addition, the experts found that overall, the propriety was also at the highest level. The standard evaluative findings of feasibility, propriety, utility, and accuracy were all found to be at the highest level. Furthermore, the propriety of the handbook for system implementation was found to be at the highest level. It was because the analysis of factor management of those systems viewed the whole systems by considering the necessary factors or resources for learning environmental management, so that the process indicated the strategy, which obviously included participation in learning environmental management, the implementation outcome as a needed goal of participatory management process in environmental situation management, and efficient and effective learning. Besides, the report identified improvement and revision as being used as feedback information for improving and developing the system. This would help all stakeholders to use the system, understand the details of each factor clearly, and view the association between factors of the system logically. This was supported by Tong-noi's (2013) study, who found that the system factors included Input, Process, Output, and Feedback. Each factor consisted of sub-factors including: administrative leadership, teacher competencies, student characteristics, learning process management, environmental situation management, and obtained resources. Process Factors consisted of program development, learning process management development, measurement and evaluation as well as transfer of learning achievement, development of educational media and technology, research for development of educational quality, educational supervision, and learning environmental assurance in authentic situation. Tong-noi (2013) found that there were the following factors: Input, Process, Output, and Feedback. Each factor consisted of the following sub-factors: administrative academic leadership, teacher competencies, student characteristics, learning process management, environmental situation management for learning, and obtained resources. Process Factors consisted of development of the school curriculum, development and learning process management, measurement and evaluation as well as transfer of learning achievement, development of educational media and technology, learning resource development and promotion, research for educational quality development, educational supervision, and internal quality assurance and educational standard. Output Factors consisted of students, teachers, and administrators. Feedback consisted of the finding report, and improvement and correction based on recommendations. This is supported by Puchsing (2010), which looked at the effectiveness in of the management system at Suksa-songkrao School. There were three factors including: 1) Input with 35 indicators; 2) Process factors consisted of task analysis, work planning, implementation of planning, performance assessment and conclusions, and 3) Output factors consisted of 47 indicators including the Feedback factors in the system. It was supported by Ru-pan (2003), for whom there were four aspects of major structures: Input, Process, Output, and Feedback factors: 1)Input factor including the objective of evaluation; 2) indicators and evaluative criteria, assessment instruments and documentation, assessors and assesses; 2) Process factor consisted of work practice planning and evaluation, data collection of work performance, data analysis and work practice evaluation, by comparing to the specified criteria, 3) Output factors consisted of the record of conclusions in work performance of Basic School Boards, overall; 4) Feedback factors consisted of feedback data for The Office of Educational Service Area based on application of evaluative system in real work practice of local school boards found that propriety in every item of system factors was at the high level. Furthermore, the evaluative findings were standardized based on work practice standard criteria regarding the evaluation of utility, feasibility, propriety, and accuracy were assessed at the "High" level in every aspect.

The findings of system usage in small sized primary schools found that: 1) the overall classroom quality was higher than $80 \% ; 2$ ) the overall quality of outside classroom learning resources was rated at the highest level; 3 ) the teachers' overall appropriate personality was rated at the highest level; 4) the good teaching behavior of teachers was rated at the highest level; 5) the desirable a characteristics of students were at the "Good and 
Excellent" levels, for 94.21\%; 6) the good relationships among teachers, students, and parents were also rated at the highest level; and 7) the levels of satisfaction with the system of related stakeholders was assessed at the highest level. These results are supported by Sarasan (2000), who found that the classroom learning environment had a high relationship with levels of satisfaction of students, significant at .01 level.

\section{Recommendations}

The administrators and stakeholders of small sized schools should study the details of participative learning environmental management for small sized Primary Schools before employing them in their schools. There should be an emphasis on Process factors in which the participatory process can be used for work implementation. If the administrators understood and could apply it in their schools, the school management would be more successful. The awareness of the system should be continuously stimulated for teachers, students, and stakeholders so that the significance of participatory management is clear in providing better learning opportunities. These can include field trips to study best practice schools for their successful implementation based on the system. Every step in the handbook should be implemented simultaneously in development for teachers, students, and stakeholders.

\section{References}

Bush, T., \& Middlewood, D. (2005). Leading and managing people in education. London: Sage.

Heick, T. (2014). 10 Characteristics of a highly effective learning environment. Retrieved June 16, 2014, from http://www.teachthought.com/learning/10-characteristics-of-a-highly-effective-learning-environment/

Lunenburg, F. C., \& Ornstein, A. C. (1996). Educational Administration: Concepts and Practices (2nd ed.). Belmont, CA: Wadsworth Publishing.

McVey, G. (1989). Learning Environment. The International Encyclopedia of Educational Teaching. Oxford: Pergamon Press PLC.

Nair. (2007). Schools for the $21^{\text {st }}$ century: Are you ready? Retrieved January 22, 2013, from http://webcache.googleusercontent.com/search?q=cache:13D6hmkW7LgJ:www.designshare.com/index.php /articles/21st-century-are-you-ready\&num $=1 \& \mathrm{hl}=\mathrm{en} \& \mathrm{gl}=$ th\&strip $=1 \& \mathrm{vwsrc}=0$

Office of the Basic Education Commission. (2007). The Guidelines of Decentralization and Educational Management for the Committee of The Office of Educational Service Area based on Ministry Rule in Determining the Principle and Technique for Decentralization and Educational Management in 2007. Bangkok: Thai Agricultural Cooperative Printing ltd.

Office of the Basic Education Commission. (2014). The Small Sized School Management. Retrieved August 6, 2014, from http://www.obec.go.th/news/36415

Office of The Education Council. (2009). The Recommendations for the Second Decade of Educational Reform. (2009-2018). Bangkok: Prigwan Graphic Printing LTD.

Pon-rung-roj, C. (2012). The Third Round School with Low Level in Assessment of Easan Small Sized Schools, A lot of Uncertified Schools. Retrieved July 13, 2012, from http://www.thairath.co.th/content/275639

Ponsima, D. (2007). Dr. Direk Ponsima's Handbook of Small Sized Schools. Retrieved February 17, 2009, from http://www.news.sanook.com/education/education_164698.php

Puchsing, A. (2010). The Development of Effective Oriented Management System in Suksa-songkrao School (Doctor of Educational Degree, Mahasarakam: Mahasarakam University).

Rooncharoen, T., \& Sri-pai-roje, W. (2011). The Development Strategy of Learning Persons. Bangkok: Kao-fang.

Ru-pan, P. (2003). The Development of Assessment System in Work Practice of Basic School Boards. Doctor of Educational Degree. Bangkok: Chulalongkorn University.

Sanrattana, W. (2013). $21^{\text {st }}$ Century Just the beginning Brighter Education, Brighter Future. Bangkok: Thipwisut Cooperative Printing ltd.

Sarasan, T. (2000). The relationships between factors of the classroom learning environment on teachers and the satisfaction of students in secondary schools (Doctor of Educational Degree, Bangkok: Srinakharinwirot University).

Schoderbeck, P. P. et al. (1990). Management system: Consideration. Boston: Richard D. Irwin.

Sergiovanni, T. (1999). The principalship: A reflective practice perspective. 4th ed. Boston: Allyn \& Bacon. 
Sri-fa, P. (2013). Learning Environmental Management. Retrieved August 21, 2013, from http://srithai.hypermart.net/environment.html

Tong-noi, N. (2013). The Development of Effective Academic Work Management in Primary School (Doctor of Educational Degree, Mahasarakham: Mahasarakham University).

\section{Copyrights}

Copyright for this article is retained by the author(s), with first publication rights granted to the journal.

This is an open-access article distributed under the terms and conditions of the Creative Commons Attribution license (http://creativecommons.org/licenses/by/4.0/). 